Int. J. Dev. Biol. 49: 355-361 (2005)

doi: $10.1387 / \mathrm{ijdb} .041956 \mathrm{mp}$

\title{
Vasculogenesis and angiogenesis in the mouse embryo studied using quail/mouse chimeras
}

\author{
MICHEL PUDLISZEWSKI and LUC PARDANAUD* \\ Institut d'Embryologie Cellulaire et Moléculaire du CNRS et du Collège-de-France, Nogent-sur-Marne, France
}

\begin{abstract}
Using quail/chick chimeras, we have previously shown that different embryonic territories are vascularized through two distinct mecanisms, angiogenesis and vasculogenesis. Angiogenesis occurs in tissues of somatopleural origin, vasculogenesis occurs in territories of splanchnopleural origin. The aim of this work was to establish if these modes of vascularization were conserved in the mammalian embryo. Since in vivo manipulations with mammalian embryos are difficult to perform, we used a quail/mouse chimera approach. Mouse limb buds of somatopleural origin, and visceral organ rudiments of splanchnopleural origin, were grafted into the coelomic cavity of $\mathbf{2 . 5}$ day-old quail embryos. After four to seven days, the hosts were killed and the origin of the endothelial cells in the mouse tissues was determined by double staining with the quail endothelial and hematopoietic cell-specific marker, $\mathrm{QH} 1$ and mouse-specific VEGFR2 and VEGFR3 probes. Our findings show that the great majority of vessels which developed in the mouse limbs was $\mathrm{QH1}^{+}$, indicating that these tissues were vascularized by angiogenesis. Conversely, visceral organs were vascularized through the vasculogenesis process by mouse endothelial cells which differentiated in situ. These results demonstrate for the first time that in the mouse embryo, as previously shown in avian species, the tissues from somatopleural origin are vascularized by angiogenesis, while rudiments of a splanchnopleural origin are vascularized by vasculogenesis, both at vascular and lymphatic levels.
\end{abstract}

KEY WORDS: vasculogenesis, angiogenesis, quail/mouse chimera

\section{Introduction}

The vascular system of the avian embryo is formed by two distinct mechanisms termed vasculogenesis and angiogenesis (Risau and Lemmon, 1988). Vasculogenesis is defined as the development of a vascular tree from intrinsic endothelial cells (EC). Vasculogenesis occurs during early morphogenesis (Pardanaud et al., 1987; Coffin and Poole, 1988; Péault et al., 1988) and during organogenesis (Pardanaud et al., 1989). Angiogenesis is defined as the colonization of a rudiment by extrinsic EC from a preexisting vascular network (Hertig, 1935). Using the quail/chick chimera model (Le Douarin, 1969), angiogenesis was shown to occur during development of the vessels of the brain (Stewart and Wiley, 1981) and the limb (Jotereau and Le Douarin, 1978; Pardanaud et al., 1989).

The initial definitions of vasculogenesis and angiogenesis were somewhat modified over the last few years. Vasculogenesis is sometimes used to describe the formation of a primitive vascular network while angiogenesis is used to describe the remodelling and maturation of this initial plexus. Thus, depending on the authors, these two processes are distinguished either by the intrinsic or extrinsic origin of EC in a vascular network (Risau and Lemmon, 1988), or by different development and maturation steps of this plexus (Risau, 1997). We will use the initial definitions of these two words.

During embryonic development, angiogenesis and vasculogenesis are at work in different territories. Angiogenesis occurs in tissues of somatopleural origin, i.e., composed of the ectoderm and the somatopleural mesoderm, while vasculogenesis occurs in territories of splanchnopleural origin, i.e., composed of the endoderm and the splanchnopleural mesoderm (Pardanaud et al., 1989). In quail/chick chimeras, when a limb bud (somatopleural origin) from one species is grafted into the coelomic cavity of a host from the other species, it is colonized by host $\mathrm{EC}$, thus, it is vascularized by angiogenesis. If a visceral organ

Abbreviations used in this paper:EC, endothelial cell; VEGF, vascular endothelial growth factor. VEGFR, VEGF receptor. 
rudiment (splanchnopleural origin) is grafted, it is not colonized by host vessels but produces its own endothelial contingent through the vasculogenesis process. These grafting experiments also demonstrated that the hematopoietic cells present in the grafted rudiments were always extrinsic and came from the host, whatever the embryonic origin of the grafts (Pardanaud et al., 1989).

The existence of two processes of vascularization operating in different embryonic territories allowed to experimentally identify, in the quail/chick chimera model, two endothelial lineages with distinct origins and potentialities (Pardanaud et al., 1996). The first one emerges in the paraxial/somitic mesoderm and gives rise to EC which migrate to vascularize by angiogenesis the neural tube, the mesonephros, the limbs and the body wall. They also form the endothelium of cardinal veins and dorsal and lateral aspects of the aorta. The second lineage differentiates in the splanchnopleural mesoderm and vascularizes the visceral organs by vasculogenesis. It also gives rise to the ventral endothelium of the aorta as well as to the ventral hematopoietic aortic clusters which correspond to the first intraembryonic site of hematopoiesis (Dieterlen-Lièvre and Martin, 1981; Jaffredo et al., 1998). The former lineage has an angiopoietic potential, i.e., it only produces $E C$, while the latter has a hemangiopoietic potential, i.e., it gives rise to both endothelial and hematopoietic cells. This hemangiopoietic potential is induced by the endoderm and inhibited by the ectoderm (Pardanaud and Dieterlen-Lièvre, 1999).
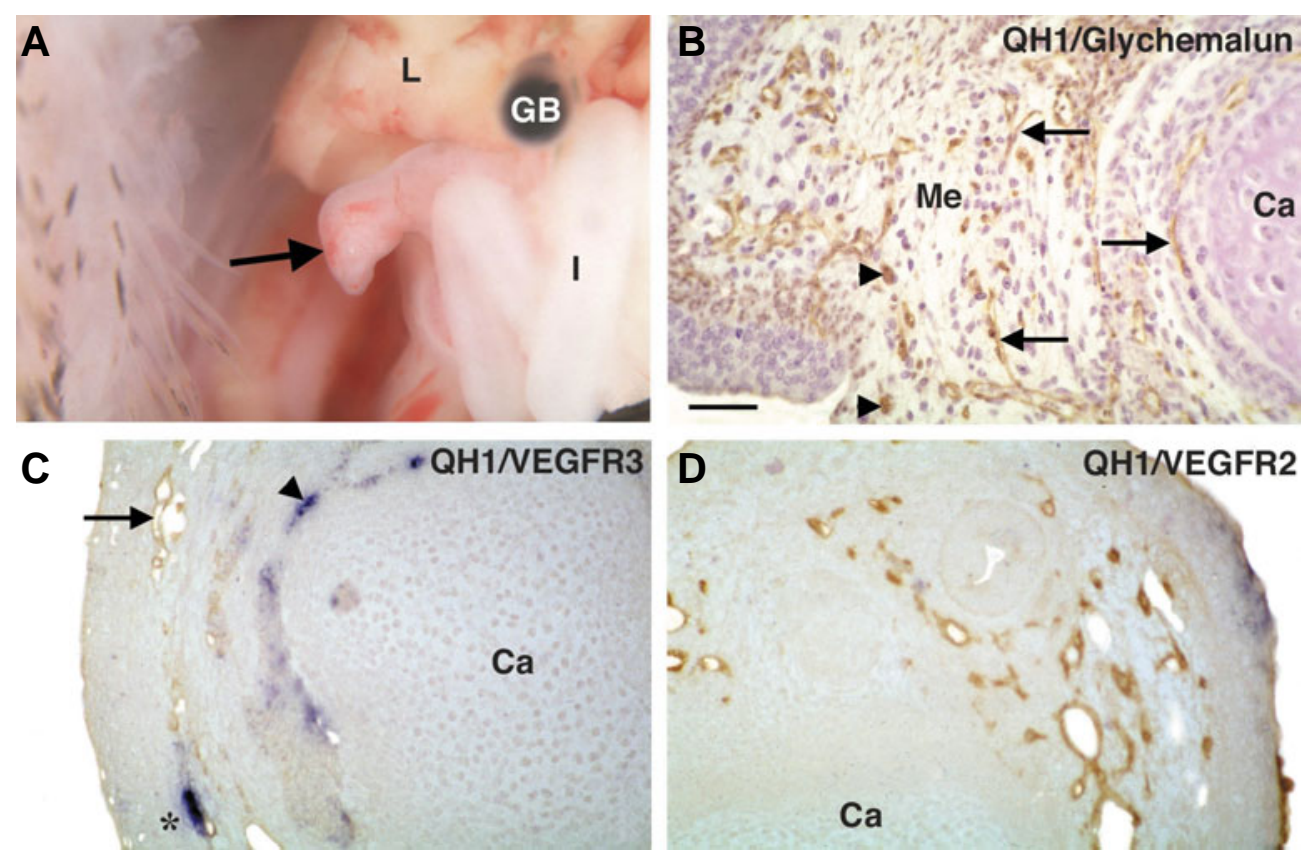

Fig. 1. Limb bud angiotenesis. (A) Mouse limb differentiated in the coelomic cavity of a quail host (5 days after the graft). The grafted limb (arrow) developed closed to the intestine (I) in the vicinity of the liver (L) and the gallblader (GB). Note the presence of a superficial vascular network. (B-D) Transverse sections of a mouse limb bud differentiated in the coelomic cavity of a quail host (7 days after the graft). (B) In the proximal region of the graft, $\mathrm{QH} 1$ immunostaining shows positive vessels (arrows) irregularly distributed around the cartilage (Ca). Some $\mathrm{QH}_{1}{ }^{+}$hematopoietic cells (arrowheads) are also present in the mesenchyme (Me). (C) In the medial part of the grafted limb, QH1/VEGFR3 double staining reveals, around the cartilage (Ca), the existence of quail $\mathrm{QH}_{1}{ }^{+}$vessels (arrow), mouse VEGFR3 ${ }^{+} \mathrm{EC}$ (arrowhead) and chimeric $\mathrm{QH}^{+}$/ VEGFR3 ${ }^{+}$endothelium (star). Note that the distribution of vessels is more organized than in the proximal region. (D) In the distalmost region of the limb rudiment, QH1/VEGFR2 double staining illustrates that the whole vascular network is composed of quail $\mathrm{OH}^{+} \mathrm{EC}$. Bar, $36 \mu \mathrm{m}$ in $\mathrm{B}-\mathrm{D}$.
Vasculogenesis also occurs during early morphogenesis in mouse embryos (Drake and Fleming, 2000). However, it appeared ult to verify whether the two distinct vascularization processes chimera model was proposed to circumvent this difficulty (Fontaineet al., 1995). The authors demonstrated that mouse somites tube orthotopically grafted into chick hosts has a trophic role on which behave ortike the grafted into quall hosts produce EC by injection of isolated murine EC into the circulation of chick embryos; in this model injected EC integrated into different host endothelia (Yamashita et al., 2000). origin. Mouse limb buds or visceral rudiments were grafted into the coelomic cavity of 2.5 day-old (E2.5) quail hosts. The mouse or quail origin of EC was determined using specific markers for each species. Quail EC were identified with the QH1 monoclonal antibody (Pardanaud etal., 1987) while the murine ECwere detected by in situhybridization with VEGFR2/VEGFR3probes. VEGF is the major growth factor controlling the emergence of endothelial precursors. The quantity of available VEGF is critical because the inactivation of one allele of this gene in the mouse is sufficient to kill the embryos early in development(E9.5E10.5) due to a poor vascularization (Carmeliet et al., 1996; Ferrara et al., 1996). The main VEGF signaltransducing receptor, VEGFR2, is a very early marker of the endothelial lineage in both avian and mouse embryos (Eichmann et al., 1993; Yamaguchi etal., 1993; Dumont etal., 1995). Targeted inactivation of VEGFR2 in the mouse results in the absence of endothelial and hematopoietic cells in homozygote embryos (Dumont etal., 1995; Shalaby et al., 1995). VEGFR3 is expressed in all EC during early ontogenesis, becoming restricted to lymphatic EC only later in development in both mouse and avian embryos (Kaipainen et al., 1995; Wilting et al., 1997). Its inactivation induces early embryonic lethality in the homozygous mutants due to cardiovascular malformations (Dumont et al., 1998). 


\section{Results}

The success of quail-mouse grafting experiments tightly depended on the age of the host. The best developmental stages were the Hamburger and Hamilton $(\mathrm{HH})$ stages 16-17 (see Hamburger and Hamilton, 1951). With younger and older host embryos the grafted explants never correctly developed, appeared necrotic and were often found free in the host coelomic cavity after 4 to 5 days. In all cases, the age of analysed murine grafts corresponded to stages where the expression of the VEGFR3 gene revealed the lymphatic identity of EC (Kaikainen et al., 1995).

\section{Limb bud grafts}

Eight limb grafts were analysed from explants isolated at 9 days post coitum, 2 were retrieved 4 days after the grafting procedure, 4 after 5 days and 2 after 7 days. The grafted limbs had attached either to the abdominal wall or to a visceral organ. Macroscopically, they looked like cartilaginous segments surrounded by a well vascularized mesenchyme and tegument. In one case, the distal part of the limb developed normally and digits were present (Fig. 1A).

Histological sections showed that mesenchymal tissue was present in younger grafted limbs while a cartilaginous axis developed in the older ones (Fig. 1BD). However, within the time frame of the experiments, bone marrow never developed. In all explants, tegument surrounded the mesenchymal tissue (Fig. $1 C, D)$. At the site of engraftment the tissues were always chimeric, composed of both quail and mouse (non-vascular) cells. The quail cells progressively disappeared in the proximal quarter of the grafts. Quail and mouse cells were easily distinguishable after QCPN or glychemalun staining. Concerning vascularization, on the total length of the grafts, the great majority of vessels was $\mathrm{QH}^{+}$, i.e., from quail host origin (Fig. 1B-D). These vessels were irregularly distributed in the proximal part of the rudiments (Fig. 1B) but progressively, they developed in a concentric ring around the cartilage (Fig. 1C, D). On sections from the proximal/medial part, a few VEGFR2 expressing vascular EC or VEGFR3 expressing lymphatic EC participated to the endothelium of chimeric vessels (Fig. 1C). In the distalmost region of the limbs, all
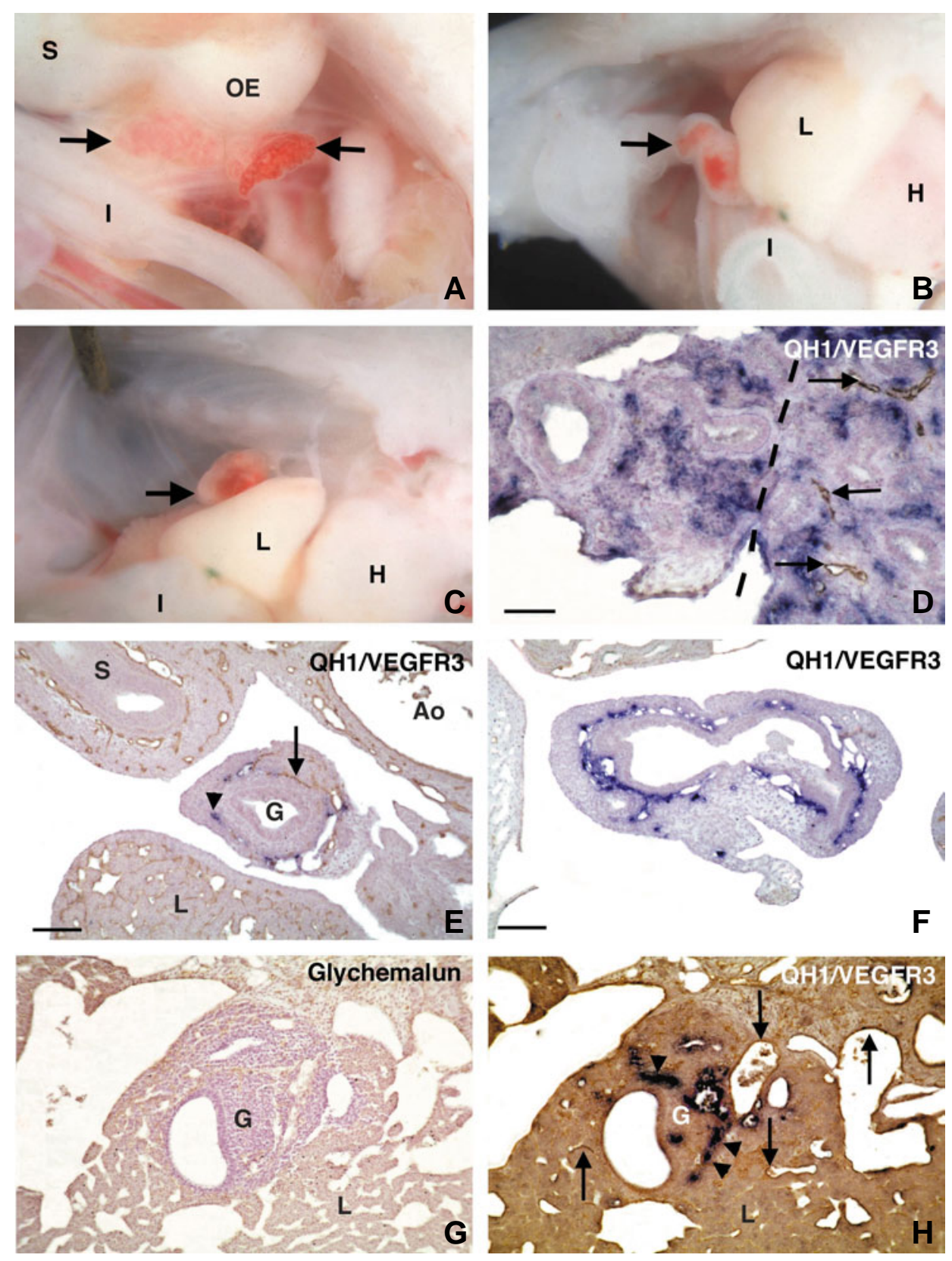

Fig. 2. Vasculogenesis in visceral organs. (A-C) General view of the grafted mouse visceral rudiments. (A) Two mouse lung rudiments (arrows) developed in the vicinity of the oesophagus (OE), the stomach (S) and the intestine (I). Four days after the graft. (B) A foregut rudiment (arrow) has developed beneath the host liver. (C) A small liver (arrow) is present in close contact to the host liver (L). Five days after the graft. $H=$ heart. (D-H) Sections of mouse visceral grafts differentiated in the coelomic cavity of a quail host (5 days after the graft). (D) QH1/VEGFR3 double staining applied onto a section of a mouse lung rudiment. The dotted line indicates the border between the proximal region on the right and the distal region on the left. VEGFR3 ${ }^{+}$vessels are present in all the lung mesenchyme, while the $\mathrm{QH}^{+}$endothelia are only detected in the proximal part of the graft (arrows). (E) OH1/NEGFR3 double staining of a section of a mouse gut in the proximal region. The graft $(G)$ is implanted on the hylum of the quail liver (L). At this level, $\mathrm{OH}^{+}$(arrow) and VEGFR3 ${ }^{+}$(arrowhead) vessels coexist. Note the $\mathrm{OH}^{+}$endothelia in the adjacent quail tissues. Ao, dorsal aorta; S, stomach. (F) In the distal part of the same gut transplant, the OH1/ VEGFR3 double staining shows numerous intrinsic VEGFR3 ${ }^{+}$EC. (G) In this case, the gut explant (G) differentiated inside the host liver (L). Glychemalun nuclear staining allows to discriminate the two tissue types. (H) In an adjacent section, QH1/VEGFR3 double staining reveals that despite the proximity of numerous $\mathrm{QH}^{+}$hepatic sinusoids (L, arrows), within the grafted tissue (G) mainly VEGFR3 ${ }^{+}$lymphatic vessels develop (arrowheads). Bars, $36 \mu \mathrm{m}$ in D, $225 \mu \mathrm{m}$ in E and $90 \mu \mathrm{m}$ in F-H. 

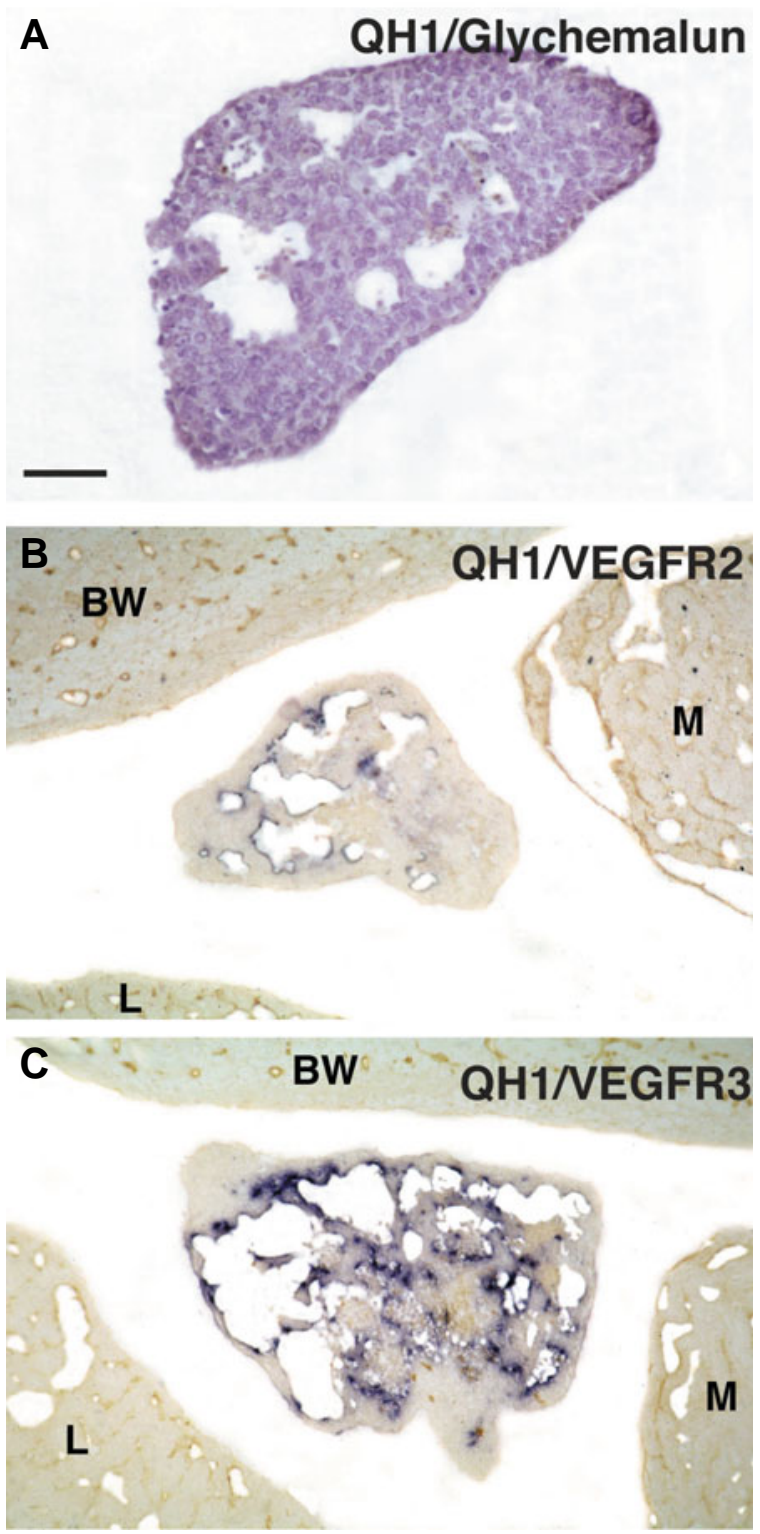

Fig. 3. Vasculogenesis in the liver. (A-C) Adjacent sections of a mouse liver rudiment differentiated in the coelomic cavity of a quail host (5 days after the graft). The $\mathrm{QH} 1 / \mathrm{g} / \mathrm{ychemalun}$ staining shows that the endothelia are negative (A) but express the mouse VEGFR2 (B) or VEGFR3 (C) genes. Note that the vascularization of the surrounding quail tissues is $\mathrm{QH1}^{+}$. BW, body wall; L, liver; $\mathrm{M}$, mesonephros. Bar, $90 \mu \mathrm{m}$.

the vascularization had a quail origin (Fig. 1D). In all grafted tissue, in the vicinity of vessels, isolated round $\mathrm{QH} 1{ }^{+}$cells, i. e., hematopoietic cells, were present (Fig. 1B).

Thus, it appeared that the great majority of vessels which vascularized the mouse limb rudiments had an extrinsic origin and came from the quail host: the vascularization of these territories was dependent on the angiogenesis process.

\section{Visceral organs}

Twelve explants isolated at 9 and 10 day post coitum were analysed 4 to 5 days after the grafting procedure. All the grafts except one had attached to the host visceral organs (Fig. 2A-C). The last one had attached to the body wall. The identity of each rudiment was clearly specified, although the shape of these organs was sometimes altered by space constraints due to the neighbouring host tissues (Fig. 2A-C). In the case of the lung, the explant appeared as a pink structure with a morphology varying from globular to cubic (Fig. 2A). In the case of the gut, a white structure with superficial tortuous vessels and small hemorrhagic regions developed (Fig. 2B) and in the case of liver, typical hepatic tissue differentiated (Fig. 2C).

\section{Lung rudiments}

The site of attachment to the host appeared narrow and was composed of chimeric tissue. When the two lung buds were dissected together from the donor mouse embryo, on sections it could be clearly seen that a piece of anterior gut developed between the organs. The histological examination of this lung tissues showed endodermic epithelia of parabronchi surrounded by mesenchyme in which numerous vessels were present. $\mathrm{QH}^{+}{ }^{+}$ endothelia were visible in the proximal part of grafts but never in the distal part where only VEGFR2 + vascular EC or VEGFR3 + lymphatic EC were detected (Fig. 2D). Sometimes, in the mesenchymal tissue surrounding the parabronchi, $\mathrm{QH} 1^{+}$cells, probably macrophages, were present (not shown).

\section{Gut rudiments}

The histology of these organs appeared simple: a festooned lumen surrounded by an endodermic epithelium and more or less mesenchyme (Fig. 2E, F). The territories of implantation were important and composed of chimeric tissues where $\mathrm{QH} 1^{+}$vessels were more numerous than VEGFR2 + vascular or VEGFR3 ${ }^{+}$ lymphatic endothelia (Fig. 2E). In these regions, the vessels were randomly distributed while in the distal part of rudiments the $\mathrm{QH} 1^{+}$ vessels disappeared and mouse VEGFR2+/VEGFR3+endothelia built a dense concentric network surrounding the endodermal epithelium (Fig. 2F). One of the grafted gut rudiments implanted and differentiated inside the host quail liver (Fig. 2G). Despite the presence of numerous $\mathrm{QH} 1{ }^{+}$sinusoids surrounding this graft, the majority of the endothelia in this explant expressed mouse VEGFR2 ${ }^{+}$and VEGFR3 ${ }^{+}$transcripts (Fig. $2 \mathrm{H}$ ).

\section{Liver rudiments}

Histological observations showed the classical hepatic structure with hepatocytes and sinusoids (Fig.3). These sinusoids were never stained with $\mathrm{QH}_{1}{ }^{+}$(Fig. 3A) and the endothelia transcribed the mouse VEGFR2 or VEGFR3 genes (Fig. 3B, C). Notably no hematopoiesis developed in these grafted rudiments.

In conclusion, the grafting experiments with different visceral organs demonstrated that these rudiments were able to produce their own contingent of EC necessary and sufficient to build a complete vascular network. Thus, in these organs, the vascularization depended on the vasculogenesis process.

\section{Discussion}

Our study demonstrates for the first time that the processes of vasculogenesis and angiogenesis operate in the mammalian embryo. We show that mouse embryonic rudiments of somatopleural origin implanted in the coelomic cavity of a quail host are vascularized 
through the angiogenesis process, while rudiments of splanchnopleural origin are vascularized through the vasculogenesis process. These results confirm previous observations in the quail-chick model (Pardanaud et al., 1989) and extend them to the mouse embryo.

To obtain chick-mouse chimeras, a mouse embryonic rudiment was isolated and grafted into ortho- or heterotopic locations in chick embryos at a homologous developmental stage (Fontaine-Pérus et al., 1995). In these conditions, myocytes derived from mouse somites were able to contact the axons of chick neurons and a mouse neural tube grafted orthotopically into a chick host enables myogenesis to proceed in the chick somites (Fontaine-Pérus, 2000). Recently, the development of teeth in chick embryos was obtained after mouse neural crest transplantations (Mitsiadis et al., 2003). In a quail-mouse model, a study showed that EC from mouse somites migrated like their quail counterparts to vascularize the neural tube, the limb, the mesonephros and the roof of the aorta (Ambler et al., 2001). This result confirmed, in the mouse, the existence of a somitic endothelial lineage which gives rise to aortic endothelium, excepting the floor of this vessel where it does not integrate, as previously demonstrated in the avian model (Pardanaud et al., 1996). Intracardiac injections of mouse EC expressing LacZ under the control of the VEGFR2 promotor into chick embryos (stages $16-17 \mathrm{HH}$ ) resulted in the formation of chimeric vessels (EC and vessel wall) in the yolk sac, the head, the heart and the intersomitic region (Yamashita et al., 2000).

Based on the homologies between quail-chick, quail-mouse and chick-mouse models, we decided to use the quail-mouse model to test if mouse embryonic tissues display different vascularization processes depending on their somatopleural or splanchnopleural origin. Visceral organ rudiments usually attached to the host visceral organs while the limb buds attached to the host visceral organs and body wall. The territories of implantation had not been analysed in the quail-chick model (Pardanaud et al., 1989). In our study, they were composed of chimeric tissue with a variable proportion of quail and mouse cells. After a proximal region of transition the quail mesenchymal cells progressively disappeared and the more distal parts of the grafts were completely constituted by mouse tissue. As observed in the quail-chick model, few isolated or grouped $\mathrm{QH} 1$ + hematopoietic cells were present in the mesenchyme of the grafts. In the lung, they corresponded to macrophages (Bienenstock, 1984).

The limb grafts were vascularized through the angiogenesis process and $\mathrm{QH}_{1}{ }^{+}$vessels were observed over their entire length. On a few sections, chimeric vessels were present. These mouse EC presumably existed in the limb mesenchyme before the dissection, but they participate poorly to the vascularization of the grafted limb. Similar observations have previously been made in the avian model (Pardanaud et al., 1989). The factor(s) which prevents the development of a vascular network from this initial intrinsic EC population is currently unknown.

Visceral organs had a completely different vascular staining pattern which corresponded to the vasculogenesis process. The territories of implantation were vascularized by a majority of quail $\mathrm{QH}^{+}{ }^{+}$vessels and some mouse VEGFR2 ${ }^{+}$or VEGFR3 ${ }^{+}$endothelia. At the level of the transition region, the quail vessels disappeared while mouse EC developed an endothelial network which became dense in the most distal part of the grafted rudiments. The mammalian visceral organs were thus able to produce an intrinsic
EC population ensuring their vascularization and preventing the invasion of host EC which were present at the proximal end of organs. It would be interesting to identify the cellular and molecular factors mediating this territorial restriction. Thus, the lung, the gut, the pancreas, the spleen and the liver (Pardanaud et al., 1989; this study) are vascularized through the vasculogenesis process and we can postulate that this is the rule in all visceral organs. However, concerning the mesonephros, the vascular process at work in this tissue is not so clearly established; depending on authors this organ is considered to become vascularized either through the angiogenesis process (Sariola et al., 1984), or through the vasculogenesis process (Robert et al., 1998). Concerning the liver, hematopoiesis never developed in the mouse grafted rudiments. This novel finding confirms the incapacity of avian hematopoietic stem cells or progenitors to colonize mouse hematopoietic rudiments, as previously established in the case of the thymus (Moore and Owen, 1967).

The finding that mouse VEGFR3 ${ }^{+}$lymphatic EC developed in the different grafted tissues, in particular in the visceral organs from intrinsic precursors, was very interesting. It confirms, in the murine model, previous studies on the ontogeny of the avian lymphatic system which showed that the lymphatic endothelium not only derived from the embryonic lymphatic sacs but also from mesenchymal lymphangioblasts (Wilting et al., 2001). In our conditions, it seemed that mouse lymphangioblasts differentiated from mesenchyme of several visceral organs.

The demonstration that mouse embryonic tissues are differently vascularized depending on their somatopleural or splanchnopleural origin raises the question whether these different processes are related to the existence of two distinct endothelial lineages in the somite and the splanchnopleural mesoderm as previously shown in the avian system (Pardanaud et al., 1996). The existence of a somitic lineage was recently confirmed in the mouse using the quail-mouse model (Ambler etal., 2001). This model could therefore possibly be used to also confirm the hematopoietic potentiality of mouse splanchnopleural mesoderm. If this lineage existed in the mouse, grafted EC should reach the ventral aortic endothelium of the host embryo and participate to the hematopoietic clusters present in the floor of the aorta. However, this demonstration would not be easy to make because the number of mouse $\mathrm{EC}$ colonizing the quail aorta appears weak (Ambler et al., 2001) and the murine EC failed to integrate into the avian ventral aortic endothelium, even they were close to it (Godin and Pardanaud, unpublished results).

The quail-mouse model presented here could be very useful to study the cellular and molecular controls of angiogenesis and vasculogenesis, in particular the role of the ectoderm and the endoderm which have respectively an inhibitory and a stimulatory effect on the emergence of EC (Pardanaud and Dieterlen-Lièvre, 1999). Furthermore, this quail-mouse model allows to follow events of differentiation using rudiments from mouse embryos, doomed to die because they lack different genes involved in the emergence and the formation of the vascular system, as recently published (Ambler et al., 2003; Hogan et al., 2004).

\section{Materials and Methods}

\section{Grafting experiments}

We used BALB-C mouse donors and Japanese quails hosts (Coturnix coturnix japonica). Mouse limb buds were retrieved from E9 embryos. 
Visceral rudiments were recovered from E10 embryos, by dissection of different portions of the intestine: anterior (future oesophagus and lung), middle (hepatic rudiment) and caudal (future intestine). Quail hosts were incubated for $60 \mathrm{~h}$ at $37^{\circ} \mathrm{C}$ to reach the developmental stages $\mathrm{HH} 16$ and 17. The vitelline membrane and the amnios were carefully removed around the right wing bud and the isolated mouse explants were placed onto the quail embryo. A longitudinal incision was made rostrally to the wing bud and the explant was introduced into the coelomic cavity of the host. The eggs were closed with adhesive scotch tape and placed at $37^{\circ} \mathrm{C}$ in a humid atmosphere. Autopsies were performed 4 to 7 days after the grafting experiment.

\section{In situ hybridization and immunohistochemistry}

Mouse explants were dissected from the host coelom together with the surrounding tissue where they had implanted. They were fixed overnight in AFA ( $60 \%$ ethanol, $30 \%$ formaldehyde, $10 \%$ acetic acid). After ethanol dehydration and toluene treatment, the grafts were embedded in paraffin and sectioned at $5 \mu \mathrm{m}$. In situ hybridization was performed as previously described (Moyon etal., 2001). Antisense riboprobes were prepared from a fragment of murine VEGFR2 (position 1347-1797) and a fragment of mouse VEGFR3 (position 2411-4154, kindly provided by K. Alitalo). After in situ hybridization, the sections were immunostained with $\mathrm{QH} 1$ and QCPN monoclonal antibodies. QCPN (Carlson and Carlson, Developmental studies Hybridoma Bank, Dept. of Pharmacology and Molecular Sciences, the Johns Hopkins School of Medicine, 725, North Wolf Street, Baltimore, MD21205) recognizes the nucleus of all quail cells. The sections were successively incubated with undiluted $\mathrm{QH} 1$ (1h at room temperature) and QCPN (overnight at room temperature) hybridoma supernatants. A goat-anti-mouse peroxydase-coupled IgG (BioRad) was used as secondary antibody and the staining was developed with diaminobenzidine (Sigma). On some slides, only the immunohistochemistry protocol (QH1 alone or both QH1/QCPN) was applied and sections were counterstained with glychemalun. On other slides, only a glychemalun nuclear staining was performed. The sections were rapidly dehydrated in $100 \%$ ethanol then in toluene and mounted in Entellan. Observations were made with a Leitz microscope.

\section{Aknowledgements}

We thank Françoise Dieterlen for her constant support throughout the elaboration of this work, Isabelle Godin and Josselyne Salaün for providing the mouse embryos, Anne Eichmann for critical reading of the manuscript, Delphine Moyon and Christiane Bréant for helpful discussions during the progression of this work. This study was supported by the CNRS.

\section{References}

AMBLER, C. A., NOWICKI, J. L., BURKE, A. C. and BAUTCH, V. L. (2001). Assembly of trunk and limb blood vessels involves extensive migration and vasculogenesis of somite-derived angioblasts. Dev. Biol. 234: 352-364.

AMBLER, C. A., SCHUNK, G. A. and BAUTCH, V. L. (2003). Stem cell-derived endothelial cells/progenitors migrate and pattern in the embryo using the VEGF signaling pathway. Dev. Biol. 257: 205-219.

BIENENSTOCK, J. (1984). The lung as an immunologic organ. Annu. Rev. Med. 35: 49-62.

CARMELIET, P., FERREIRA, V., BREIER, G., POLLEFEYT, S., KIECKENS, L., GERTSENSTEIN, M., FAHRIG, M., VANDENHOECK, A., HARPAL, K., EBERHARDT, C., DECLERCQ, C., PAWLING, J., MOONS, L., COLLEN, D., RISAU, W. and NAGY, A. (1996). Abnormal blood vessel development and lethality in embryos lacking a single VEGF allele. Nature 380: 435-439.

COFFIN, J. D. and POOLE, T. J. (1988). Embryonic vascular development: immunohistochemical identification of the origin and subsequent morphogenesis of the major vessel primordia in quail embryos. Development 102: 735-748.

DIETERLEN-LIÈVRE, F. and MARTIN, C. (1981). Diffuse intraembryonic hemopoiesis in normal and chimeric avian development. Dev. Biol. 88: 180-191.
DRAKE, C. J. and FLEMING, P. A. (2000). Vasculogenesis in the day 6.5 to 9.5 mouse embryo. Blood 95: 1671-1679.

DUMONT, D. J., FONG, G. H., PURI, M. C., GRADWOHL, G., ALITALO, K. and BREITMAN, M. L. (1995). Vascularization of the mouse embryo: a study of flk1 , tek, tie and vascular endothelial growth factor expression during development. Dev. Dyn. 203: 80-92.

DUMONT, D. J., JUSSILA, L., TAIPALE, J., LYMBOUSSAKI, A., MUSTONEN, T., PAJUSOLA, K., BREITMAN, M. and ALITALO, K. (1998). Cardiovascular failure in mouse embryos deficient in VEGF receptor-3. Science 282: 946-949.

EICHMANN, A., MARCELLE, C., BRÉANT, C. and LE DOUARIN, N. M. (1993) Two molecules related to the VEGF receptor are expressed in early endothelial cells during avian embryonic development. Mech. Dev. 42: 33-48.

FERRARA, N., CARVER-MOORE, K., CHEN, H., DOWD, M., LU, L., O'SHEA, K. S., POWELL-BRAXTON, L., HILLAN, K. J. and MOORE, M. W. (1996). Heterozygous embryonic lethality induced by targeted inactivation of the VEGF gene. Nature 380: 439-442.

FONTAINE-PÉRUS, J. (2000). Mouse-chick chimera: an experimental system for study of somite development. Curr. Top. Dev. Biol. 48: 269-300.

FONTAINE-PÉRUS, J., JARNO, V., FOURNIER LE RAY, C., LI, Z. and PAULIN, D. (1995). Mouse chick chimera: a new model to study the in ovo developmental potentialities of mammalian somites. Development 121: 1705-1718.

HAMBURGER, V. and HAMILTON, H. L. (1951). A series of normal stages in the development of chick embryo. J. Morphol. 88: 49-92.

HERTIG, A. T. (1935). Angiogenesis in the early human chorion and in the placenta of the macaque monkey. Carnegie Contrib. Embryol. 25: 37-81.

HOGAN, K.A., AMBLER, C.A., CHPMAN, D.L. and BAUTCH, V.L. (2004). The neural tube patterns vessels developmentally using the VEGF signaling pathway. Development 131: 1503-1513.

JAFFREDO, T., GAUTIER, R., EICHMANN, A. and DIETERLEN-LIĖVRE, F. (1998). Intraaortic hemopoietic cells are derived from endothelial cells during ontogeny. Development 125: 4575-4583.

JOTEREAU, F. V. and LE DOUARIN, N. M. (1978). The development relationship between osteocytes and osteoclasts: a study using the quail-chick nuclear marker in endochondral ossification. Dev. Biol. 63: 253-265.

KAIPAINEN, A., KORHONEN, J., MUSTONEN, T., VAN HINSBERGH, V.W., FANG, G.H., DUMONT, D., BREITMAN, M. and ALITALO, K. (1995). Expression of the fms-like tyrosine kinase 4 gene becomes restricted to lymphatic endothelium during development. Proc. Natl. Acad. Sci. USA 92: 3566-3570

LE DOUARIN, N. M. (1969). Particularités du noyau interphasique chez la caille japonaise (Coturnix coturnix japonica). Utilisation de ces particularitès comme «marquage biologique» dans les recherches sur les interactions tissulaires et les migrations cellulaires au cours de l'ontogenèse. Bull. Biol. Fr. Belg. 103: 435-452.

MITSIADIS, T.A., CHÉRAUD, Y., SHARPE, P. and FONTAINE-PÉRUS, J. (2003). Development of teeth in chick embryos after mouse neural crest transplantations. Proc. Natl. Acad. Sci. USA. 100: 6541-6545.

MOORE, M.A. and OWEN, J.J. (1967). Experimental studies on the development of the thymus. J. Exp. Med. 126: 715-726.

MOYON, D., PARDANAUD, L., YUAN, L., BRÉANT, C. and EICHMANN, A. (2001). Plasticity of endothelial cells during arterial-venous differentiation in the avian embryo. Development 128: 3359-3370.

PARDANAUD, L., ALTMANN, C., KITOS, P., DIETERLEN-LIÈVRE, F. and BUCK, C. A. (1987). Vasculogenesis in the early quail blastodisc as studied with a monoclonal antibody recognizing endothelial cells. Development 100: 339-349.

PARDANAUD, L. and DIETERLEN-LIÈVRE, F. (1999). Manipulation of the angiopoietic/hemangiopoietic commitment in the avian embryo. Development 126: $617-627$.

PARDANAUD, L., LUTON, D., PRIGENT, M., BOURCHEIX, L. M., CATALA, M. and DIETERLEN-LIĖVRE, F. (1996). Two distinct endothelial lineages in ontogeny, one of them related to hemopoiesis. Development 122: 1363-1371.

PARDANAUD, L., YASSINE, F. and DIETERLEN-LIÈVRE, F. (1989). Relationship between vasculogenesis, angiogenesis and haemopoiesis during avian ontogeny. Development 105: 473-485.

PÉAULT, B., COLTEY, M. and LE DOUARIN, N. M. (1988). Ontogenic emergence of a quail leukocyte/endothelium cell surface antigen. Cell. Differ. 23: 165-174.

RISAU, W. (1997). Mechanisms of angiogenesis. Nature 386: 671-674. 
RISAU, W. and LEMMON, V. (1988). Changes in the vascular extracellular matrix during embryonic vasculogenesis and angiogenesis. Dev. Biol. 125: 441-450.

ROBERT, B., ST JOHN, P. L. and ABRAHAMSON, D. R. (1998). Direct visualization of renal vascular morphogenesis in Flk1 heterozygous mutant mice. $\mathrm{Am} . \mathrm{J}$. Physiol. 275: F164-172.

SARIOLA, H., PÉAULT, B., LE DOUARIN, N., BUCK, C., DIETERLEN-LIÈVRE, F. and SAXEN, L. (1984). Extracellular matrix and capillary ingrowth in interspecies chimeric kidneys. Cell. Differ. 15: 43-51.

SHALABY, F., ROSSANT, J., YAMAGUCHI, T. P., GERTSENSTEIN, M., WU, X. F., BREITMAN, M. L. and SCHUH, A. C. (1995). Failure of blood-island formation and vasculogenesis in Flk-1-deficient mice. Nature 376: 62-66.

STEWART, P. A. and WILEY, M. J. (1981). Developing nervous tissue induces formation of blood-brain barrier characteristics in invading endothelial cells: a study using quail-chick transplantation chimeras. Dev. Biol. 84: 183-192.
WILTING, J., EICHMANN, A. and CHRIST, B. (1997). Expression of the avian VEGF receptor homologues Quek1 and Quek2 in blood-vascular and lymphatic endothelial and non-endothelial cells during quail embryonic development. Cell Tissue Res. 288: 207-223.

WILTING, J., PAPOUTSI, M., OTHMAN-HASSAN, K., RODRIGUEZ-NIEDENFUHR, M., PROLS, F., TOMAREV, S.I. and EICHMANN, A. (2001). Development of the avian lymphatic system. Microsc. Res. Tech. 55: 81-91.

YAMAGUCHI, T. P., DUMONT, D. J., CONLON, R. A., BREITMAN, M. L. and ROSSANT, J. (1993). Flk-1, an flt-related receptor tyrosine kinase is an early marker for endothelial cell precursors. Development 118: 489-498.

YAMASHITA, J., ITOH, H., HIRASHIMA, M., OGAWA, M., NISHIKAWA, S., YURUGI, T., NAITO, M. and NAKAO, K. (2000). Flk1-positive cells derived from embryonic stem cells serve as vascular progenitors. Nature 408: 92-96. 